\title{
READING DIFFICULTIES IN CHILDREN
}

\author{
BY \\ MILDRED CREAK, M.D., M.R.C.P., \\ Physician-in-charge of Children's Department, Maudsley Hospital, London.
}

With an unimpaired sensory equipment and normal intelligence, every child learns to speak, and subsequently to read, write and spell his own language, so that his thought comes habitually to be verbally expressed. A study $^{1}$ of what was thought to be a case of congenital auditory imperception, but subsequently found to be a case of partial deafness, demonstrated the extent to which the various faculties required in achieving language are inter-related. In this patient, what was admittedly a severe degree of deafness but by no means a total deafness, led to a complete inability to acquire spoken language, the power to read, and to spell. Most of the individual letters were learned and remembered, but there was no facility at all for combining these into writing. A striking point in this case (an intelligent, partially-deaf, eight-year-old girl) was that her ability to hear and discriminate between different kinds of noises was excellent, but her deafness, affecting mainly the tone range covered by human speech, caused her own speech to be impaired and made her rely on sight and lip-reading for understanding. What bears on the present problem is the way in which the hearing loss had prevented her from learning to read, write or spell. For instance, the colour ' blue,' which she recognized, was named 'blulo,' but spelled 'lube', and on another occasion 'bube.' In such ways her productions resembled those of children who, with apparently complete sensory equipment, have the utmost difficulty in learning to read. Ewing ${ }^{2}$, describing his group of children with high frequency deafness, noted their failure in language development, and similar examples are given in the literature relating to congenital auditory imperception (Worster Drought and Allen $^{3}$, Barton Hall ${ }^{4}$, and others).

A recent paper by Schonell ${ }^{5}$, from Goldsmith's College illustrates another side of this question of the inter-relation of functions in the faculty of speech. This deals with 'the relation between defective speech and disability in spelling.' Articulatory speech defects occurred in a large percentage (11 per cent.) in his group which consisted of 105 cases of specific spelling disability representative of a school population of $\mathbf{7 , 0 0 0}$ children. For instance, one child wrote :-

'The voxhe scrswie gro sue and wie gro viin, and we gro ruin and we gro groin. Sue fo no gin the sci, the due 5 . Wie go in the vor and we cin we oio and uci wie go ba rine cothe, and co ba. Cuco wie sdand in the all and one of the sithe cu the civo no the dovo, the du the is of theco.'

Transcription.

' The Forster School we do sums and we do writing and we do drawing. Some of us get the stick, about 5. We go in the hall, we 
sing, we pray, and next we go back in the classroom and go back. Sometimes we stand in the hall, and one of the teachers tells the story out of the Bible-the story of the Israelites.'

This example was from what Schonell called an instance of 6 intense paraphemia' in which there was a lowered power of auditory discrimination in the realm of speech, although the cases studied could hear and understand spoken words. He speaks of the concomitant effect of backwardness in reading, but gives no figures indicating the extent to which reading was also affected. The point of common interest lies in this further corroboration of the close linkage between spoken language, hearing capacity, and the ability to learn to read, to write and to spell.

In spite of the extensive literature (see Jastak's paper ${ }^{6}$ ) now accumulating on this problem, there is still some confusion of thought and much difference of opinion as to the fundamental nature of the disability. The lay mind, and most important, perhaps, the teacher, tends to assume that children who do not learn to read are obstinate, or stupid, probably both. This adds to the child's difficulties, in that an attitude of scolding and disapproval comes to be associated with his reading lessons, and to some extent with all school activities. The figures given in this study, and those of other observers, confirm the impression, however, that the difficulty is certainly not confined to children with a general lack of intellectual ability. Nor does it appear to be the result of an inhibition primarily determined by emotional factors. Such an inhibition is certainly not the only cause, and probably not a common cause in the earliest stages of the condition. Later, no doubt, the ordinary child develops an attitude of resistance towards a subject which he finds difficult, although other children of his own age can learn it without any particular effort.

\section{Mechanics and teaching of reading.}

Before describing the investigations made on a group of cases seen at the Maudsley Hospital, a brief description of the mechanics and methods of teaching reading is given, together with some of the theories held to account for difficulties in learning to read. The idea of the investigation itself developed out of a study of these theories. The elementary school child usually receives some very simple instruction in reading and letters when he first reaches school and in a nursery school he may learn something of the kind before he is five. In English elementary schools, serious reading lessons begin as a rule when the child is about six. In preparatory schools of the modern kind, children may learn to read at five and teaching methods vary a good deal. The alphabet is no longer taught; letters are learned in association with pictures of common objects, and in the more modern type of school, the 'look and say' or sentence method is generally used. This encourages the child to recognize words, or larger units, as a whole, and to proceed from this to analysis of letter combinations, and their respective sound values. The fact that school is only begun at six years in the United States and that these methods are almost everywhere taught is thought to be the cause of the greater frequency of reading difficulties there as compared 
with this country. In Germany the condition is much less frequent than here, perhaps because almost everywhere a phonetic method is used from the start, i.e., linking sounds to letters, and because of the more rational phonetic spelling.

The psychology of reading has been investigated, a good summary of this work being Vernon's book$^{7}$, which has a full bibliography. She is mainly concerned with the mechanics which go to make a successful, facile reader. Certain points stand out, and have some bearing on the many theories which are held to account for the cases of difficulty.

The eye movements have been studied, and it appears that in all purposive looking the eye moves in a series of jerks directed towards focussing the object on the macula; during movement vision is not registered, so that to introspection, the eye appears to reach its object in a single sweep. In reading the jerks occur in a horizontal fashion with small backward lags, or even small movements in a reverse direction. Such wandering and wasteful movements are much more frequent in children who are just beginning to read, and resemble the irregular vocal ' reading aloud' of the bad reader. They are also more noticeable in reading material which is difficult of comprehension, and more so still when reading senseless jargon, or a foreign language, emphasizing the extent to which the mind, from familiarity with the written word, forestalls hesitation by guesswork.

Huey $^{8}$ worked on an analysis of the important features determining the recognition of a word, such as the alternation of vertical letters and curved letters, using a tachistoscopical method, and there seems little doubt that, whatever the method taught, the end result in all normal readers is to recognize 'word-wholes,' rather than individual letters, proceeding to analysis by associated visual images.

\section{Previous theories.}

This leads on to the position taken up by the Gestalt psychologists, discussed in a recent paper by Frank ${ }^{9}$ on children with reading disability. She investigated three groups of children from London elementary schools: infants beginning to learn reading, children with pronounced reading disability, and a control group of normal readers. In the group of young children she found a tendency to confuse letters of great similarity such as $u-v, m-n, b-d$, and a tendency to remember the general configuration of a letter or word rather than its direction and orientation in space. In matching picture patters, the most frequent mistake was to confuse one pattern with its mirror image. Such children were also unable to synthesize different sounds and letters into a word, and similarly had difficulty in separately recognizing the individual letters in a word. In giving her conclusions she draws attention to the well-known faculty some children possess of recognizing apparently identical objects such as different gramophone records, or the notation of a song without being able to read music. Her conclusions are that it is typical of the infantile perception to see wholes, to recognize shape and solidarity of an object, rather than to perceive detailed differences in the direction, for instance, of component parts. She found that the poor readers tended to reproduce very similar errors, and she suggests that the backward reader is one who remains ' on a relatively immature level of perception, and therefore implies that this fusion of wholes is a method of perception which the normal child outgrows. Her remedial work aimed at teaching and encouraging the child to improve its recognition of whole words and sentences. It is interesting that this 
view is almost diametrically opposed to that of a group of American psychologists, and to Hinshelwood, who advocates the phonic method in re-educating these children.

Since Hinshelwood ${ }^{10}$ first drew attention to these cases (although many isolated examples had been published prior to this), there has been a desire to postulate an organic basis to account for the findings. His book begins with a description of a case of acquired word-blindness with right homonymous hemianopsia. He notes the failure to recognize words, to remember and name the individual letters, to link letter-sounds into words, that is to write and to spell, and the ready fatigue and variable attention which accompanied efforts to do so. The lost associations were extremely difficult to re-form, but the localization of the lesion limited its effects to letters as symbols, the memory for figures and recognition of them remaining intact. He then describes a group of children in whom a somewhat similar condition, without hemianopsia, existed. In one, the familial occurrence was striking and to him suggested a developmental anomaly. He implies that such an anomaly must exist and differentiates between the severe case for which the term congenital word blindness should be reserved, and suggests congenital dyslexia for children who merely find it difficult to learn to read. He makes no analysis of the types of mistakes most commonly made, and does not suggest that there may be gradation, rather than a difference in kind, between the severe and the mild case.

Orton' $\mathrm{s}^{11}$ theory involves the conception of different levels of cerebral function, postulating that the ability to perceive visual stimuli and to register that perception, is located in cells around the calcarine fissure of the occipital lobes, and that localization is arranged, by means of the decussation of the optic tracts, in such a way that the right visual field in both eyes is represented at the right occipital pole, and the left field at the left pole. At a higher level, in the physiological sense, and probably located immediately peripheral to the calcarine fissure is a visual-recognitive area, bilateral destruction of which causes visual agnosia, that is, the nonrecognition of perceived objects, while the third level, the visual-associative, gives the recognition and understanding of written symbols, that is to say, of words, the area concerned being the left angular gyrus when the left is the dominant hemisphere. He suggests that visual memory patterns, or engrams, are formed in both hemispheres, those in the dominant hemisphere being the ordinary right-handed form of the written word, and those in the so-called silent hemisphere being the mirror image, thus CAT and TAJ, and that the brain learns to suppress the mirror image. $\mathrm{He}$ similarly supposes that the pattern of kinaesthetic memory images may be disturbed so that a tendency to move from the centre of the body outwards, as in writing with the right hand, and reading from left to right, may, be altered to a sinistrad direction, as in mirror writing with the left hand.

With this theory he attempts to explain the frequency of what he calls ' static' reversals of letters, for instance ' $b$ ' being confused with ' $d$,' ' $p$ ' being confused with ' $q$,' and ' kinetic' reversals of words or parts of words, such as ' saw' being read as ' was,' and 'ton' being written or read as ' not.' Children with a reading difficulty often misread such a word as ' tarnish,' saying ' tarshin,' and they show a greater facility than the normal child for mirror reading.

Here, therefore, is a relation to the question of dominance. One of the few facts that is generally accepted in this question of speech localization, is that in right-handed people the hemisphere controlling the more highly perfected motor movements, is also the hemisphere in which the speech centre is located. Tests have been devised to establish ocular dominance. There is a good deal of evidence that man has a leading or preferential eye, 
as definitely chosen from the other as is the leading hand. Obviously eye dominance of which the subject is unaware, is less likely to be interfered with' by education, and so may be a fairer test of lateral dominance as a whole. Some interest attaches therefore to the relatively high proportion of left-eyed children who have reading difficulties. On testing the handedness, and 'eyedness' of normal children, and those with difficulties in reading, there is a greater proportion of mixed dominance. To explain this more fully, the normal person is right-handed, and right-eyed. But a few people are left-handed and left-eyed. But some normal people, and a rather larger proportion than normal of cases of reading difficulty, are right-handed and left-eyed, or left-handed and righteyed. It is certainly an observed fact that the group of children with reading difficulties tend to show this mixed dominance in higher proportion, and are often unduly late in establishing manual dominance, or there may be a history of left-handedness in near relatives.

According to Orton this is due to a developmental delay in assigning dominance to one hemisphere, and consequently to a longer persistence of the tendency to reverse directions in reading and writing, and so to the persistence of a difficulty in eliding the reversed image and consequent confusion and difficulty in reading. In Monroe's ${ }^{12}$ cases, and in the material described in this paper it will be seen that the children with reading difficulty did show a relatively high proportion of mixed dominance. It is by no means clear, however, that this fact by itself would be regarded as evidence of the validity of Orton's interesting but speculative theory. As has been shown, Frank would interpret it otherwise. Dearborn ${ }^{13}$ has compared and recorded the eye movements in normal readers, and children with reading disability, and has emphasized other ocular factors, such as muscular imbalance, and Selzer ${ }^{14}$ has added to the theories by his work on suspenopsia, or alternating vision, a point which he relates to lateral dominance. A recent article by Eames ${ }^{15}$ attempts an anatomical corroboration by assuming that longer association paths must exist, with greater liability to interference, when hand and eye preferences are situated in and controlled from different hemispheres.

In attempting to assess the value of these theories, the absence of exact knowledge is more striking than their validity. Each investigator describes a number of cases and brings forward evidence, so that each theory is up to a point supported by well-documented clinical findings. Of these, the anatomical may be expected to be hard to find, since these children live and outgrow their condition, and it appears as unreasonable to look for measurable developmental failure here, as in, say, a case of outstanding lack of musical appreciation. The impression which gradually evolved during the present investigation is that all the theories have some bearing, and that none is wholly satisfactory because the cases do not fall into a single category. This only serves to emphasize again the complex factors involved in the acquisition of a written language. Thus, the recognition of arbitrary but accepted symbols, the formation of linkages between these and auditory images and memories, the kinaesthetic factors, notably in writing, and the intelligence and interest which the child brings to bear on the problem, must all play a part. 


\section{Present investigation.}

This particular study was undertaken with a view to seeing how far these cases of reading disability could be compared with other forms of aphașia, both congenital and acquired, particularly with reference to the views and theories put forward in the literature. It was carried through with the help and co-operation of Dr. W. Mayer-Gross, to whom I am indebted for many suggestions, both in actual procedure, and in analyzing the results.

The material (fifty cases) was obtained from the Children's Out-patient Department at the Maudsley Hospital. The method of selection was to take those children who were referred for difficulty in school work, or in whom, after initial interviews with the psychiatrist and psychologist, such difficulties appeared to be present. It is the usual procedure, in all cases referred to this clinic, for the psychologist to give an intelligence test, comprising the Burt revision of the Binet-Simon scale, some performance tests, and a selection of Burt's educational tests, and the children in this series either complained of a difficulty in reading, or were found by testing to have a reading age two or more years retarded below their mental age. Thus a simple range of tests can give a summarized picture of a child's abilities and attainments. Typical examples, given below, can be transcribed into graphic form, to which Munroe gave the name of ' educational profile', (table 1).

TABLE 1 .

TyPiCAL EDUCATIONAL PROFILES.

\begin{tabular}{|c|c|c|c|c|c|c|}
\hline $\begin{array}{l}\text { CASK } \\
\text { AND } \\
\text { SEX }\end{array}$ & $\begin{array}{l}\text { Chrono } \\
\text { LOGICAL } \\
\text { AGE }\end{array}$ & $\underset{\text { Mantal }}{\text { Mental }}$ & I. Q. & $\begin{array}{c}\text { READING } \\
\text { AGE }\end{array}$ & $\begin{array}{c}\text { ARITH- } \\
\text { MRTIC } \\
\text { AGE }\end{array}$ & \\
\hline $\begin{array}{l}\text { K.C. } \\
\text { M. }\end{array}$ & $9 \frac{9}{12}$ & $99_{1:}^{10}$ & 102 & $5_{1: 2}^{9}$ & 10 & Typical reading disability \\
\hline${ }^{2}$ D.H. & $8{ }_{12}^{9}$ & $8 \stackrel{8}{12}$ & 98 & $6_{12}^{\overline{7}}$ & $7_{12}^{4}$ & $\begin{array}{l}\text { Less severe case with some general } \\
\text { learning disability }\end{array}$ \\
\hline $\begin{array}{l}\text { E. McC. } \\
\text { M. }\end{array}$ & 11 & $8{ }_{1}^{6}:$ & 77 & $6_{12}^{6}$ & 9 & $\begin{array}{l}\text { General backwardness, but arith- } \\
\text { metic well up to (actually } \\
\text { above) mental age though still } \\
\text { below chronological age }\end{array}$ \\
\hline $\begin{array}{c}\text { 1). R. } \\
\text { F. }\end{array}$ & $10_{\mathrm{T} 2}^{7}$ & $8_{12}^{7}$ & 80 & $88_{12}^{6}$ & $8_{12}^{6}$ & $\begin{array}{l}\text { General backwardness; both read- - } \\
\text { ing and arithmetic barely up to } \\
\text { mental age }\end{array}$ \\
\hline
\end{tabular}

Special tests.-The following scheme of special tests was evolved by Dr. Mayer-Gross, with the idea of estimating the various capacities utilized by the child in learning to read, but arranged, so far as possible, without the use of letters. They were usually described by the children as ' puzzles.' 
A series of cards was made in duplicate bearing arbitrary patterns, using straight lines, dots or geometric figures. One set was placed on the table, and the child was asked to match each one with the duplicate set of identical cards handed out to him. This test was within the intellectual capacity of both the youngest and the dullest child seen, and it at once became obvious that in ordinary ability to recognize a simple visual pattern, these children were not significantly below the average. More mistakes were made by mentally dull children than by those who, in reading, frequently would confuse what seemed to us relatively simpler shapes, such as $b$ and $d$.

They were then asked to copy a pattern made from coloured mosaics, and then reproduce the pattern from memory. Here a few children tended to get the general configuration of the pattern correct, but would make a mistake in direction, although this never extended to making a true ' mirror image' pattern. Out of the fifty children tested, only five tended to alter the direction only, and of these five one was a borderline case with an I.Q. of 70 .

The children were then asked to listen to a simple rhythm, tapped on the desk, and to reproduce this rhythm; in many cases, the memory for such a simple auditory pattern was excellent, but in some, often the restless and hyperactive children, the pattern would soon be lost. One particularly interesting group, discussed below, was singled out by this test.

To estimate how far kinaesthetic factors were involved, and whether the children could recognize by touch, the shape of letters and figures, a series of wooden capital letters was used. After making sure that these could be named by sight, the child was blindfolded and given a letter in the hand. Also after getting the child to write down the numerals, again to make sure that these were known, a selection of numbers was traced on the dorsum of the hand with a blunt pencil, and the child's arm passively moved in the air to form a numeral, both tests being done with the child blindfolded. He was then asked to ' guess' what had been ' written.'

Only six children showed any marked tendency to reverse the numbers in writing them to dictation. This is in contrast to the persistent tendency to reverse letters such as $b$ and $d$. Some of the younger children failed to understand the directions, and in the group as a whole, the results were not sufficiently consistent to give any very significant information. What again became clear was that many children, who failed to recognize written letters visually, and who made mistakes both in writing and reading them, had no such difficulty with figures.

It must be understood that these tests were not applied with the idea that statistical results would be forthcoming. They are not standardized tests, but they served the purpose of illustrating the extent to which ancillary factors in the acquisition of reading remain intact in children who yet fail to learn to read.

In the older children, and those who could make some attempt at reading, the tests described by Monroe $^{16}$ as Iota word test, and Word discrimination test were used. These are useful for drawing attention to the tendency these children have to confuse 'mirror-image' letters such as $b$ and $d, p$ and $q$, to reverse directions reading 'not' for ' ton' and the present results tallied with hers, although the small numbers debarred any attempt at statistical analysis. Each child was also tested for handedness, and eyedness, both by the psychologist, and on another day, by the author. The validity of the eyedness tests was not certain, but using the same tests, on separate occasions, the results of both investigators tallied perfectly.

\section{Results.}

The sex distribution shows a preponderance of boys over girls, this being a usual finding in all investigations relating to speech and language 
ability. Orton ${ }^{16}$ brings this into his work on stammering, suggesting that the greater prevalence of this in males is an effect in the motor and kinaesthetic component of speech in the same way that severe reading disability is a failure in the visual component. It is interesting to note that stammering is known to follow attempts to make a naturally left-handed child use his right hand, perhaps by dispossessing the newly-acquired habitation of the speech centres. In the present series of fifty cases, there were thirty-eight boys with ages ranging from 6.3 years to $14 \cdot 8$ years, and twelve girls with ages ranging from $7 \cdot 6$ years to $13 \cdot 1$ years. In Monroe's series, the preponderance of boys (84 per cent.) over girls (16 per cent.) is even higher. Handedness, and eyedness tests gave the results shown in table 2. These figures can usefully be compared with a similar group of

TABLE 2.

HANDEDNESS AND EYEDNESS.

\begin{tabular}{|c|c|c|c|c|c|}
\hline & & & Maudsley cases & M. Monroe cases & CONTROLS \\
\hline R. H. AND R. E. & & & $\begin{array}{c}\text { Per cent. of } \\
\text { total } \\
24^{*}\end{array}$ & $\begin{array}{c}\text { Per Cent. OF } \\
\text { TOTAL } \\
47^{*}\end{array}$ & $\begin{array}{c}\text { Per CENT. OF } \\
\text { TOTAL } \\
59^{*}\end{array}$ \\
\hline R. H. AND L. E. & $\cdots$ & $\cdots$ & $18)$ & 35 & 21) \\
\hline L. H. AND R. E. & $\ldots$ & $\ldots$ & $12\}^{\dagger}$ & $3 \int^{\dagger}$ & $6 \int^{\dagger}$ \\
\hline L. H. AND L. E. & $\ldots$ & $\ldots$ & 12 & 8 & 5 \\
\hline R. H. AND AMBI E. & $\ldots$ & $\ldots$ & 6 & 6 & 9 \\
\hline L. H. AND AMBI E. & $\ldots$ & $\ldots$ & 2 & 1 & $\mathbf{0}$ \\
\hline Ambi H. AND R. E. & $\ldots$ & $\ldots$ & 16 & 一 & 一 \\
\hline AMBI H. AND L. E. & $\ldots$ & ... & 8 & 一 & 一 \\
\hline AMBI H. AND AMBI E. & & $\ldots$ & 2 & - & - \\
\hline
\end{tabular}

Compare ${ }^{*}$ with $\dagger$ in pathological and normal cases.

cases, and controls cited by Monroe in her book. The point to note is the relatively high percentage of mixed dominance, that is L.H. and R.E. or R.H. and L.E., compared with those children who were fully right or left dominant.

In the fifty cases studied, the range of intelligence quotients showed wide variations (table 3).

TABLE 3.

INTELLIGENCE QUOTIFNTS.

$\left.\begin{array}{cc}\text { I. } Q . & \text { No. OF CASES. } \\ 70-80 & 13 \text { CASES } \\ 80-90 & 20 \text { CASES } \\ 90-110 & 16 \text { CASES } \\ \text { OVER } 110 & 1 \text { CASE }\end{array}\right\} \quad \begin{aligned} & \text { DULL AND BACKWARD GROUP. } \\ & \text { NORMAL GROUP. }\end{aligned}$

In a smaller group of twentý-one cases, selected for more intensive study, six cases have an I.Q. of over 100, the highest being 107 (two cases), 
thirteen cases have I.Q.'s between 83 and 98, and only two have I.Q.'s of 73, these two being included because of special points in the family history. This is a usual distribution for London elementary school children, and suggests that there is no dearth of material among the ordinary school population.

The rhythm test separated out a small group of interesting cases. It was found that out of the fifty children, nine, who showed no difficulty in any other test, failed completely in this one. Table 4 shows that these

TABLE 4.

RHYThM TEST SUB-GROUP.

\begin{tabular}{|c|c|c|c|c|}
\hline Name & AGE & I.Q. & $\begin{array}{l}\text { AGE ON } \\
\text { TALKING }\end{array}$ & MOTOR AND SPEECH ABNORMALITIES \\
\hline $\begin{array}{l}\text { JoHN S. } \\
\text { EDWIN S. } \\
\text { DENYS S. } \\
\text { HARRY L. } \\
\text { BRIAN H. } \\
\text { HENRY H. } \\
\text { ARTHUR H. } \\
\text { JoHN D. } \\
\text { SIDNEY O. }\end{array}$ & 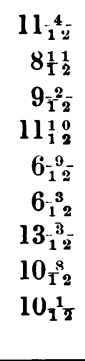 & $\begin{array}{r}102 \\
95 \\
89 \\
107 \\
103 \\
93 \\
86-90 \\
112 \\
94\end{array}$ & $\begin{array}{c}\text { NEARLY 3' } \\
\mathbf{2} \mathbf{2}-3 \\
\mathbf{2} \\
\text { NORMAL } \\
\mathbf{3} \\
\mathbf{3} \\
2 \\
2+ \\
2+\end{array}$ & $\begin{array}{l}\text { Slight stammer and speech defect. } \\
\text { Restless and fidgety. } \\
\text { Aggressive-has had slight chorea. } \\
\text { Left-handed and clumsy. } \\
\text { Stammers, twitch (tic) of face. } \\
\text { Fidgetty and aggressive. } \\
\text { Speech defect and slight, deafness. } \\
\text { Motor control very poor. } \\
\text { Motor control poor; has squirming } \\
\text { movements. }\end{array}$ \\
\hline
\end{tabular}

were all children of good intelligence, with noticeable hyperkinesis, and with one exception outstandingly late in learning to talk. The association of a failure in auditory memory with retarded speech suggests an auditory factor. Whether or not the hyperkinetic tendencies are more marked in this group than in others is not yet clear. A number of these children are certainly hyperkinetic, with poorly executed movements and often the description of ' fidgety, restless, and inattentive' is given by the school. The degree of hyperkinesis was sufficient to be noted as increased in the summaries of twenty-two of the present fifty cases. This is naturally difficult to standardize or estimate quantitatively, and the apparent clumsiness often interferes very little with actual achievement of something the child likes doing, such as performance tests, jig-saw puzzles, or building bricks. Sometimes, however, this restless inattention has been noticeable during testing, and being such an outstanding trait might well have led to yet another theory as to the causation of reading disabilities.

All the children show mistakes which make Orton's theory a tempting one; and no other 'school' has attempted to explain the extraordinary frequency of certain confusions and the way in which all types seem to repeat certain standard errors. It would seem as if, bearing in mind only similarity, such words as ' sun' and ' sum' ' tool' and ' fool' might be confused. 'And yet such a mistake was never noted, although ' saw' and 'was' were often confused. In Monroe's analysis of errors, while the 
children with a reading disability, and normal children learning to read, produced the same errors in many cases, the reversals, confusion of mirrorimage letters, and palindrome words were in excess, and tended to persist, and to be repeated in subsequent tests, in the children who had a marked degree of reading disability.

Auditory factors are certainly present in some cases, and without an audiometer it is extremely difficult to make any accurate hearing test in young children. It seems certain, however, that difficulties in auditory discrimination and reproduction may occur even with apparently perfect hearing, and Schonell's work indicates the extent to which imperfect speech and auditory imagery for words may affect spelling. In two of the present cases it has been possible to get an audiometer test done.

Both boys had what was regarded loosely as 'normal hearing.' Both made mistakes in words, for instance A. H. heard ' southern' as 'sudden,' and 'Mars' as ' mask,' and is slipshod in his own enunciation of words. The other boy, L. O., pronounced poorly, and he misheard several words in a vocabulary test; he could not analyze words into their constituent sounds. In this case, reversals and confusion of seen letters were not at all marked, for instance he had no difficulty in distinguishing $b, d$ and $p, q$. An audiogram of both these boys shows a small loss in auditory acuity affecting the area of tones used in human speech.

Certainly all these children have great difficulty in blending sounds into words, and in analyzing a difficult word into its constituent sounds. A common reply is ' I don't know that one' to a rather more difficult word, the child not yet having grasped that reading as a process is universally applicable, once the linkage between sound and letter has been accomplished.

Finally, the question of the importance of the family history was considered.

Hinshelwood, describing his famous group of cases, had under observation a family including four brothers, none of whom succeeded in learning to read while at school. The children, a boy and a girl, of an elder sister of these boys, also experienced the greatest difficulty with reading. In all six cases, the difficulty was specific for reading, and in other ways the children seemed bright and intelligent.

In the present series, the family history was studied from two aspects, namely, the question of left-handedness, with or without stammering, and the presence of severe difficulty in reading in either parent, their siblings and offspring or grandparents. The significance of this is impossible to assess with any accuracy, since remarks were often of a general kind, such as ' he was always slow in school.' In few cases could the relative, of whom this was said, be interviewed, and it was often forgotten whether the 'slowness' referred particularly to reading. Accepting this low standard of accuracy, there was a positive family history in seventeen of the fifty cases. In six cases, there was left-handedness in one or more near relative (as above), and in three further cases, this left-handedness went with an observed difficulty in learning to read, and in eight cases there had been some members of the family with difficulty in learning to read or in school work generally. 
Emotional aspects.

Something remains to be said concerning the emotional aspects of the problem. While not wishing to claim for this condition of reading disability the degree of specificity with which some authors have endowed it, yet it seems clear that these cases are too much alike, too clear-cut, the familial tendency too marked, to allow of an explanation on a neurotic basis alone. Hollingworth ${ }^{17}$, and in a recent paper Blanchard ${ }^{18}$, have rightly pointed out the extent to which children who are emotionally disturbed may become unable to progress in school work. In this clinic some children have been seen, with almost complete inhibition of all the normal learning processes.

Such a boy was R. G., aged 9. His mental age was 8 , reading age, $7_{12}^{2}$, and arithmetic age, 6-7 years. He was a moody, over-quiet, preoccupied child, obviously worried and compensating for this by living in a world of fantasy. His arithmetic was as severely retarded as his reading. When he could be persuaded to emerge from his fantasy life, his performance, though requiring an abnormal amount of encouragement and stimulation, gave results not far below that of a normal child of his age, although in school, at nine years old, he could barely keep up with seven year old children. He showed none of the restless inattention, or aggressive over-compensation which came to be associated with the children tested and found to have a specific reading disability.

At this stage in the investigation cases could certainly be distinguished in which emotional tension had become expressed as a symptom, in one child, in reading difficulties, in another child as motor disturbances such as tics, and in another as, say, a regression to nocturnal enuresis. Further, the secondary neurosis, which certainly does occur, and may be due to many factors, must be taken into account. By the time the case reaches the clinic, the child has usually been accepted as ' silly' by fellow pupils and backward by his teachers. His grotesque compositions, such as that given below in the case of A. H., are held up to the class for ridicule. What is perhaps worse is when he is regarded as obstinate, and constantly receives such reports as ' could do better if he tried,' and ' lacks concentration.' The fact is, that, like all true aphasics, his memory for words and letters is erratic, and his associations, made one day, are forgotten the next, while his attention is extremely readily fatigued. In this connection, one feels that Head's description of his re-education of aphasics might be circulated in schools. Such difficulties may carry over into the home situation, where he is outstripped by younger siblings. Parents may either be sceptical of his efforts, or over-anxious and inclined to blame the school, or, having had a similar difficulty themselves may show concern at having handed on such a tendency, or may advocate that the child be left to ' grow out of it' as they have probably done. These children therefore tend to dislike all school, and so to truant, or to play the fool while there, or they may attempt to over-compensate by an interest limited to handwork or games. They cease to have any interest in books, and behaviour problems may develop in association with unoccupied leisure within or outside school hours. 
In so far as these children have any sort of emotional difficulty common to the group, it would seem to be an aversion to effort showing itself in distractibility, restlessness and lack of interest in books, and granted some common basis for the initial difficulty in reading, it is easy to see how the habitual evasion of that difficulty will tend to set up faulty associations, and a persistence of these, until the mistakes become a habitual reaction. Not the least interesting part of the remedial teaching and re-education of these children is the effort which must be made to begin the new ' reading' work on lines and material far removed from that to which the child has become so drearily and pessimistically accustomed.

\section{Detailed case records.}

The three case studies show examples of differing types. In A. H. the personality problem is uppermost, and after careful observation it is concluded that it seems to be primary rather than secondarily determined by his school failure. In J. D. the hyperkinesis was so marked that his writing showed a decided tremor. There is over-compensation in the form of boasting jocularity. J. R. has a stable temperament and illustrates the effects of familial incidence. His progress with coaching is less rapid than would be expected with such an intelligent and willing pupil.

Arthur H., aged $13^{3} \cdot{ }^{3}$, had a mental age on performance tests of $11 \frac{{ }^{6}}{1^{2}}$ or higher. His reading age was $61_{12}^{10}$, and spelling age $7_{12}^{2}$. At his age the Binet scale is inapplicable because of reading being a necessity. He was a peculiar shy introverted boy, persistently truanting from school, often bullied or teased by other boys, fond only of woodwork, and of going to the cinema. In hospital he tended to evade any difficulty, but was co-operative provided he was encouraged and stimulated. Otherwise he would 'slack' and be slovenly in his appearance. His power of verbal expression was poor and he made mistakes. For instance, telling a story he said, ' once upon a boy, there was a boy,' and ' he killed the gold head that lays the gold eggs,' noticing no error. He copied correctly, but his written composition was almost unintelligible. He was told the 'Cowboy Story'-

A cowboy went to San Francisco with his dog, which he left at a friend's house while he went to buy a new suit of clothes. Dressed up in his grand new suit he came back to the dog, whistled to it, called it by its name and patted it. But the dog would have nothing to do with him, and did not know him until he changed back into the old suit of clothes.

His version ran as follows:-

He went to with his bog which he laft as a fnleds whil he went to buy a mew soit of coset Destir in his gramd mew soit he came back to the dog whicld to it called it bay it name and part it bag the dog wood not have nufist to d with him in new hat and coat. 
Another composition of his ran:-

Dear Mother I has a very happy Xams. There has been a pary in hour ward we had rot factd for dinner.

(Dear Mother, I had a very happy Christmas. There has been a party in our ward, we had roast turkey for dinner.)

His progress with coaching was completely erratic and words learned one day would be completely forgotten the next. He realized his difficulties, often reading longer words such as ' gramophone' more easily than a word like - thought.' His evasive, aloof attitude rendered special teaching a laborious and all but futile procedure.

John D., aged $10^{\frac{8}{2}}$, had a mental age of $111_{15}^{5}$, I.Q. of 107 and reading age of $7 \frac{8}{12}$. A boastful hyperkinetic boy, with great difficulty in reading, he could spell orally but his written spelling was atrocious. He was concerned about his school failure. At the clinic he ' showed off,' had many comic mannerisms, and only under pressure produced writing or spelling or would agree to read. He guessed wildly, and once broke off to say ' my brother got a prize for this.' He was explicit about this jealousy towards the younger sibling: 'I noticed the difference when he came but I've got over minding.' He showed jerky, poorly controlled movements; his associated movements were much increased, writing was shaky, but drawing and handwork were generally very good. He improved slowly and steadily with coaching, but for a long time failed in grasping configuration of letters, and mechanics of reading. Now aged $11_{1^{6}}^{6}$ he is up to standard in school, except in spelling, which is still erratic.

Jack R., aged $8^{\frac{2}{12}}$, had a mental age of $7 \frac{11}{12}$, I.Q. of 97, and reading age of 4.8. He was quiet, stolid boy, big for his age, happy and popular in school. He was good at oral work, backward in reading and all written work. His mother was intelligent, but herself could not read until aged twelve. Her sister was late in reading and a brother, now a master carpenter working from blue prints, could not read till sixteen, hence secondary anxiety in the mother at having handed on her peculiar difficulty. The boy was for long ambidextrous, but is now right-handed and right-eyed. He frequently confused $b-d, p-q$, and occasionally reversed figures. He mistook vowels reading ' melk' for ' milk, ' sun' for ' sin,' and read ' crad' for 'card.' He showed an excellent attitude, interested and plodding, to coaching, but progressed only slowly at first. He is now only sixteenth in class of thirty-six.

Thanks are due to Dr. E. Mapother, Medical Superintendent of the Maudsley Hospital, for permission to publish these cases and to Dr. W. Mayer-Gross and Dr. E. Guttmann for their help and constructive criticism in the investigation.

\section{REFERENCES.}

1. Creak, E. M., J. Neurol. \& Psychopath., London, 1932, XIII, 133.

2. Ewing, A. W. G., Aphasia in Children, London, 1930.

3. Worster-Drought, C., \& Allen, I. M., J. Neurol. \& Psychopath., London, 1929, IX, 193, 289.

4. Barton Hall, S. \& M., ibid., 1931, XI, 304. 
5. Schonell, F. J., Brit. J. Educat. Psychol., London, 1934, IV, pt. II.

6. Jastak, J., Psychol. Bull., Princeton, 1934, XXXI, 244, 272.

7. Vernon, M. D., The Experimental Study of Reading, Cambridge, 1931.

8. Huey, E. B., Am. J. Psychol., Ithaca, 1901, XI, 283.

9. Frank, H., Brit. J. Educ. Psychol., London, 1935, V, pt. I, 41.

10. Hinshelwood, J., Congenital Word Blindness, London, 1917.

11. Orton, S. T., Arch. Neurol. \& Psychiat., Chicago, 1925, XIV, 581, 615.

1\%. Monroe, M., Children Who Cannot Read, Chicago, 1932.

13. Dearborn, W., Proc. Am. Ass. Mental Deficiency, Boston, 1933, 268.

14. Selzer, C. A., Harvard Monog. in Education, No. 12, Cambridge, Mass.

15. Eames, T. H., Am. J. Orthopsychiat., Menasha, 1934, IV, 524.

16. Orton, S. T., Arch. Neurol. \& Psychiat., Chicago, 1929, XVIII, 671.

17. Hollingworth, L. S., Special Talents \& Defects, Boston, 1923.

18. Blanchard, P., Amer. J. Orthopsychiat., Menasha, 1935, V, 361. 